\title{
Erweiterung des Treuhandpartnernetzes in Rapperswil-Jona/Zürichsee
}

Die AEGERTER+BRÄNDLE AG für Steuer- und Wirtschaftsberatung ist seit bald 40 Jahren ein ausgewiesenes Treuhandunternehmen mit Sitz in Rapperswil sowie Niederlassungen in Arbon und Wattwil. Ihr Team umfasst rund 20 Mitarbeiterinnen und Mitarbeiter.

Das umfangreiche Dienstleistungsangebot konzentriert sich auf die Revision von juristischen Personen, die Gründung von neuen Gesellschaften sowie deren Umstrukturierung, qualifizierte Steuerberatung mitsamt einer umfassenden Steuerplanung, Führung von Kundenbuchhaltungen, Personaladministration und Unternehmensberatung. Die geschäftsführenden Partner verfügen über eine langjährige Beratererfahrung und verkehren dank ihrer eigenen Unternehmertätigkeit auf Augenhöhe mit ihrer anspruchsvollen Klientschaft.

$\mathrm{Zu}$ den Kunden zählen seit der Gründung viele Ärzte - und damit sind die Berater mit dem Lebenszyklus einer Arztpraxis von der Gründung bis zur Nachfolgeregelung in allen Facetten vertraut. Ob der Arzt alleine, in einer Gemeinschaftspraxis oder als Belegarzt praktiziert: AEGERTER+BRÄNDLE kennen sich aus. Sie sind Ärzten kompetente Ansprechpartner in sämtlichen finanziellen Angelegenheiten und evaluieren aus der Vielzahl von Gestaltungsformen die massgeschneiderte Lösung. Bereits vor mehr als 10 Jahren haben sie die ersten Arztpraxen in die Rechtsform der Aktiengesellschaft überführt.

Für den neuen Vertrauenspartner FMH Treuhand Services ist Kompetenz der treibende Erfolgsfaktor für

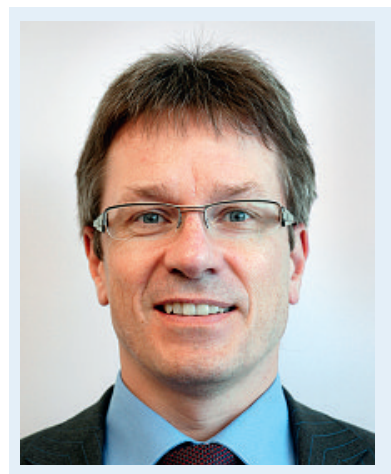

Patrick Brändle, Partner Betriebsökonom FH

dipl. Steuerexperte und dipl. Treuhandexperte Patrick Brändle ist seit über 20 Jahren in der Treuhandbranche tätig und betreut seit über 10 Jahren Ärzte.

patrick.braendle@fmhtreuhand.ch seine Tätigkeit. Dazu erneuert er sein Wissen stetig und trainiert die ausgeprägte Fähigkeit zum vernetzten Denken. Dabei handelt er praxisgerecht und lösungsorientiert. Das persönliche Gespräch ist der Ausgangspunkt der Beratung. Es schafft Vertrauen und klärt die Bedürfnisse.

AEGERTER+BRÄNDLE AG für Steuer- und Wirtschaftsberatung begleitet Sie bei Ihrem Start in die Selbständigkeit und unterstützt Sie beim Aufbau des Rechnungswesens, führt für Sie die Finanzbuchhaltung und erledigt die Personaladministration. Die ausgewiesenen Fachleute betreuen Sie in Steuerfragen und schaffen auch in komplizierten Verhältnissen Klarheit.

Patrick Brändle und Urs Aegerter sind Ihre FMH Treuhand Services-Ansprechpartner bei der AEGERTER+BRÄNDLE AG für Steuer- und Wirtschaftsberatung. Sie freuen sich zusammen mit ihrem jungen, aber dennoch langjährigen Mitarbeiterteam, Sie umfassend zu betreuen und als zuverlässiger Partner im Treuhandbereich zu begleiten.

\section{AEGERTER+BRÄNDLE}

AG für Steuer- und Wirtschaftsberatung FMH Treuhand Services

\section{Zürcherstrasse 82}

8640 Rapperswil-Jona SG

Tel. 05522057 75, Fax 0552205770

www.aegerter-braendle.ch

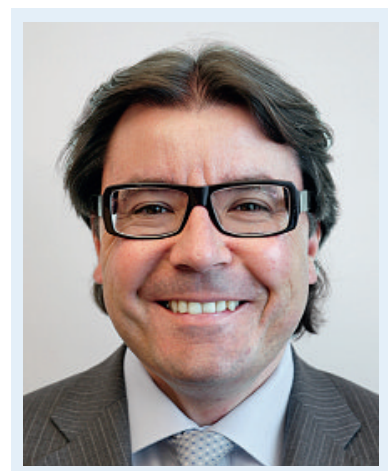

Urs Aegerter, Partner Betriebsökonom FH dipl. Wirtschaftsprüfer Urs Aegerter ist seit 15 Jahren der Ansprechpartner für Ärzte in finanziellen Fragen.

urs.aegerter@fmhtreuhand.ch 